\title{
Perceptions of Sexual Violence in Dating Relationships: Presentation Medium and Couple Characteristics
}

\author{
Emily Plackowski ${ }^{1}$, Debra Hull ${ }^{2} \&$ John Hull $^{2}$ \\ ${ }^{1}$ Department of Psychology, Oregon State University, Corvalis, Oregon, United States \\ ${ }^{2}$ Department of Psychology, Bethany College, Bethany, West Virginia, United States \\ Correspondence: Debra Hull, Department of Psychology, Bethany College, Bethany, WV 26032, United States.
}

Received: July 22, 2020

doi:10.11114/ijsss.v8i6.4936
Accepted: October 10, $2020 \quad$ Available online: October 22, 2020

URL: https://doi.org/10.11114/ijsss.v8i6.4936

\begin{abstract}
Undergraduate students evaluated scenarios depicting violence in a long-term dating relationship —in either video or written form, and involving either a male or female aggressor in either a same- or other-gender relationship. Other than the genders of the victims and assailants, the details of the scenarios were identical. Results showed that participants rated written scenarios as more powerful than video scenarios and believed that sexual assault was more likely to have happened in the written than in the video scenarios. Compared to men, women were more emotionally impacted by the scenarios, thought sexual assault was more likely to have happened, were more likely to think the aggressor wanted to have sex with the victim, and were less likely to think the victim wanted to have sex with the aggressor. Participants who rated other-sex scenarios thought sexual assault was more likely to have occurred, that the aggressor more likely wanted to have sex with the victim, and that the victim less likely wanted to have sex with the aggressor than those rating same-sex scenarios. When women were portrayed as the victims, regardless of relationship type, the scenario was more emotionally evocative. On average, participants strongly agreed that sexual assault had occurred in each of the scenarios.
\end{abstract}

Keywords: sexual assault, sexual violence, gender orientation, dating relationships

\section{Introduction}

\subsection{Introduction of the problem}

Although estimates vary some, studies generally show that about one in five women and one in 20 men report having been sexually assaulted (Black et al., 2011). College-age women experience the highest rates of sexual assault, but within this age group, college women have lower victimization rates than similarly-aged women who are not in college. Men who are in college experience a higher sexual assault rate than similarly-aged men who are not in college (Sinozich \& Langton, 2014

\subsection{Relevant Scholarship}

Research shows that the gender of the victim impacts people's perceptions about sexual violence. For instance, in one of the earliest studies to vary the genders of sexual assault victims and assailants, researchers found that participants believed women raping men to be the most pleasurable and least stressful of the conditions for the victim (Smith et al, 1988). Later, Hull et al. (2016) found that both men and women were more likely to view a male aggressor-female victim than a female aggressor-male victim scenario as rape.

The incidence of sexual violence involving male victims is less well known and its sequelae less well understood (McEvoy, 2017). In one survey, male survivors of sexual assault indicated that $67 \%$ of their attackers were women and $35 \%$ were other men (Office of the Chancellor, 2014). Davies et al. (2006) found that participants thought a male victim was more to blame than a female victim when he was attacked by someone of the gender he found attractive, with heterosexual male victims of a female perpetrator blamed more than any other victim type. Ollen et al. (2017) found that sexual minority members of their focus groups thought sexual assault was less likely in gay than heterosexual relationships and that the barriers to reporting and seeking help were similar to those for heterosexual victims.

Perpetrators of sexual violence are commonly known to their victims. A National Crime Victimization Survey analysis found that women, aged 18-24, knew their attackers about $80 \%$ of the time (Sinozich \& Langton, 2014). According to the National Institute of Justice, college women who experienced sexual assault reported knowing their attacker in 
85-90\% of cases. About 50\% of the time, the women were on a date with their attackers (National Institute of Justice, 2008). While over half of victims were raped by a current or former partner (Black et al., 2011), most rape and sexual assault research has focused on stranger rape, involving victims and attackers who have either never met, or have only just met (Smith et al., 1988; Hull et al., 2016).

Almost all research on date rape asks participants to respond to a written description. In a notable exception, Sleed et al. (2002) compared the assignment of blame in three vignettes presented in either written or video form. Results showed no difference in believability, but video scenarios were rated significantly more emotionally evocative than written ones. Researchers concluded that written vignettes might be better for measuring rape stereotypes and myths, and video vignettes might be better for researching the contexts and emotions of rape.

\subsection{Research Design and Hypotheses}

Our research investigated participants' evaluation of scenarios portraying sexual violence in college-aged dating couples. In order to address some of the research limitations identified previously, we included same- and other-gender scenarios presented in either video or written form. The couples were described as being in a long-term relationship, and scenarios were presented in both video and written form. Additionally, questions asked by Sleed et al. (2002) regarding the emotional impact of the experimental conditions were included. Based on prior research, we hypothesized that the video presentations would have a greater emotional impact than the written scenarios, but that the written and video scenarios would be equally powerful (Sleed et al., 2002), and that participants would be less likely to identify sexual assault as having happened in the same-gender than in the other-gender scenarios (Hull et al., 2016).

\section{Method}

\subsection{Participants}

Six hundred ten college students from a mid-sized public university served as participants, and were recruited via mass e-mailing, announcements in classes and student organization meetings, the enticement of extra credit, and entrance into a raffle for gift cards. Eleven hundred fifty-seven students accessed the study's Qualtrics account; 610 provided usable data.

Demographic information gathered after the study showed that most participants were undergraduates $(98 \%)$, with a mean age of $21.4(S D=5.59)$, from a variety of majors. Sixty-six percent identified as female, $24.8 \%$ as male, and $1.5 \%$ as nonbinary. Seventy-three percent identified as hetero, $11 \%$ as bisexual, $2.5 \%$ as lesbian, $1 \%$ as gay, and $4.3 \%$ as otherwise-oriented. Eighty-three percent identified as white, and $4 \%$ as Native-American, with all other racial identities accounting for less than $1 \%$ of the total. Most respondents described themselves as Democrats or politically unaffiliated.

\subsection{Materials}

The first author wrote four scripts depicting a sexual assault scenario involving a couple that had been dating and was celebrating their anniversary: Male Aggressor-Female Victim; Male Aggressor-Male Victim; Female Aggressor-Female Victim; and Female Aggressor-Male Victim. The scripts were identical except for which person was portrayed as the aggressor, and which the victim; the names and pronouns used to refer to the aggressor and victim; and the explicit particulars of the sexual intercourse situations.

The names of the characters were chosen by looking at the top American baby names of 1997—a year in which many of the participants would have been born. Name pairings in the scenarios were chosen to be phonetically dissimilar, and paired as follows: Mike/Sarah, Chris/Jake, Jessica/Beth, and Megan/Josh.

Final scripts were reviewed and edited by a small group of knowledgeable advisors, including a college-aged man and woman with histories of abuse, a licensed professional counselor trained in trauma therapy with extensive experience counseling survivors, an attorney with extensive experience prosecuting and defending family and relationship crimes, a college-aged member of the LGBTQ+ and non-binary community with a history of relationship abuse, and participating student actors.

Four fully-briefed actors - two men, and two women - were chosen. For consistency of body language and body appearance, one man and one woman portrayed the victims in two scenarios, and the second male and female actors portrayed the aggressors in two scenarios. This made for more consistent "victim" and "aggressor" acting across the four scenarios. Efforts were made to make the four videos as similar as possible in terms of timing, movement, and body language. Videos were recorded in silhouette in order to increase the universality of the portrayed experiences by removing factors like race, hair color, makeup, clothing style, and individual attractiveness, and to increase the actors' level of comfort.

Audio was dubbed later, using one male and one female actor to portray the victims and another male and female actor to portray the assailants. The resulting audio files ended up being very uniform across conditions, as voice actors were able to read their lines from a script in the recording booth. Researchers edited the video scripts into written, prose conditions. 
Efforts were made to make the described behaviors as similar as possible to those depicted in the videos.

\subsection{Procedure}

Each participant either read or watched a scenario depicting sexual assault involving a couple who had been dating and were celebrating their anniversary. The scenarios were identical except for which person was portrayed as the aggressor (the man or the woman), and which the victim (the man or the woman). Each participant was randomly presented with one of the eight conditions in a 2 (presentation mode-video or written) x 2 (gender of the aggressor) x 2 (relationship type) design.

After watching or reading the scenario, all participants evaluated the scenario by responding to a series of Likert items using a 1-7-point scale. In their ratings, participants indicated how powerful they thought the scenario to be, how likely it reflected sexual assault, how emotionally impactful it was, how likely they thought the aggressor wanted to have sex with the victim, and how likely they thought the victim wanted to have sex with the aggressor.

After completing their ratings, participants provided demographic information, and were given the opportunity to comment if they wished. All aspects of the study, including the consent form, random presentation of one of the scenarios, Likert items, demographic questions, debriefing, resources for any participant who was troubled by the content of the project, and an external link for participants to enter the gift card drawing were presented via Qualtrics, in order to guarantee anonymity to the participants.

\section{Results}

\subsection{Data Analysis}

Initially, responses to each of the Likert items were analyzed in 2 presentation style (written or video) $\mathrm{x} 2$ aggressor gender (male or female) x 2 relationship type (same- or other-gender) x 2 gender of the participant (male or female) using separate analyses of variance.

\subsection{Analysis for Presentation Style}

Surprisingly, there were main effects for presentation style in four areas, each main effect suggesting that the written presentation was more powerful than the video presentation. Using 7-point rating scales ranging from $1=$ strongly disagree to $7=$ strongly agree, participants rated the written description as more likely to reflect sexual assault $(F(1$, $600)=7.69 p=.006, \eta \mathrm{p}^{2}=.013 ; M$ written $=6.72, S D=.78 ; M$ video $\left.=6.52, S D=.99\right)$, more emotionally evocative $\left(F(1,600)=16.58 p<.001, \eta \mathrm{p}^{2}=.027 ; M\right.$ written $=5.66, S D=1.07 ; M$ video $\left.=5.25, S D=1.44\right)$, more likely to suggest that the aggressor wanted to have sex with the victim $\left(F(1,600)=7.69 p=.002, \eta \mathrm{p}^{2}=.015 ; M\right.$ written $=6.57$, $S D=1.36 ; M$ video $=6.16, S D=1.88)$, and less likely to suggest that the victim wanted to have sex with the aggressor $\left(F(1,600)=13.33 p<.001, \eta^{2}=.022 ; M\right.$ written $=1.41, S D=1.29 ; M$ video $\left.=1.88, S D=1.85\right)$. Because of the very small group sizes and the consistent presentation effects, presentation styles were combined for further analyses.

\subsection{Analysis for Likelihood that Sexual Assault Occurred}

A main effect for gender of the participant showed that women were more likely to think that sexual assault occurred in the scenarios than were men, $F(1,546)=23.48 p<.001, \eta \mathrm{p}^{2}=.02 ; M$ men $=6.37, S E=.068 ; M$ women $=6.78, S E$ $=.042$. An interaction between gender of the aggressor and gender of the victim showed that participants thought that sexual assault more likely occurred in other- than in same-gender relationships, $F(1,546)=13.27 p<.001, \eta \mathrm{p}^{2}=.04 ; M$ male with male $=6.42, S E=.086 ; M$ male with female $=6.76, S E=.078 ; M$ female with male $=6.66, S E=.079 ; M$ female with female $=6.42, S E=.077$.

\subsection{Analysis for Emotional Impact}

Main effects for the emotional impact of the scenarios showed that women were more emotionally impacted by reading the scenarios than were men, $F(1,544)=33.92 p<.001, \eta \mathrm{p}^{2}=.06 ; M$ men $=5.03, S E=.097 ; M$ women $=5.70, S E$ $=.059$, and that participants were more emotionally impacted when the victim was a woman than when the victim was a man, $F(1,544)=5.86 p=.041, \eta \mathrm{p}^{2}=.008 ; M$ male victim $=5.25, S E=.083 ; M$ female victim $=5.48, S E=.078$. A gender of the aggressor by gender of the victim interaction showed that the greatest impact was for either men or women aggressing against a woman, followed by a woman aggressing against a man, with the least emotional impact coming when a man was aggressing against another man, $F(1,544)=6.81 p=.009, \eta \mathrm{p}^{2}=.001 ; M$ male with male $=$ 4.81, $S E=.14 ; M$ male with female $=5.77, S E=.086 ; M$ female with male $=5.26, S E=.133 ; M$ female with female $=$ $5.62, S E=.082$.

\subsection{Analysis for Aggressor Wanted to Have Sex with the Victim}

A main effect for participant gender showed that women were more likely to think the aggressor wanted to have sex with the victim than were men, $F(1,545)=10.34 p=.001, \eta \mathrm{p}^{2}=.02 ; M$ men $=6.19, S E=.115 ; M$ women $=6.62, S E$ 
$=.07$. An interaction between gender of the aggressor and gender of the victim showed that participants were more likely to think the aggressor wanted to have sex with the victim in other- than in same-gender relationships, $F(1,545)=$ $27.91 p<.001, \eta \mathrm{p}^{2}=.05 ; M$ male with male $=5.98, S E=.144 ; M$ male with female $=6.75, S E=.13 ; M$ female with male $=6.77, S E=.133 ; M$ female with female $=6.12, S E=.131$

\subsection{Analysis for Victim Wanted to Have Sex with the Aggressor}

A main effect for participant gender showed that men were more likely to think the victim wanted to have sex with the aggressor than were women, $\mathrm{F}(1,545)=15.58, \mathrm{p}<.001, \eta \mathrm{p}^{2}=.03 ; \mathrm{M}$ men $=1.83, \mathrm{SE}=.105 ; \mathrm{M}$ women $=1.35, \mathrm{SE}$ $=.064$. An interaction between gender of the aggressor and gender of the victim showed that participants were more likely to think the victim wanted to have sex with the aggressor in same- than in other-gender relationships, $\mathrm{F}(1,545)=42.46 \mathrm{p}$ $<.001, \eta \mathrm{p}^{2}=.07 ; \mathrm{M}$ male with male $=1.16, \mathrm{SE}=.132 ; \mathrm{M}$ male with female $=1.16, \mathrm{SE}=.119 ; \mathrm{M}$ female with male $=1.22$, $\mathrm{SE}=.121 ; \mathrm{M}$ female with female $=1.91, \mathrm{SE}=.119$.

\section{Discussion}

Despite past research (Sims et al., 2007; Sleed et al., 2002) that suggested video vignettes might be more emotionally impactful than written scenarios, our results showed that written descriptions of sexual violence had a greater impact on participants than video presentations. After reading a written description, participants were more likely to think sexual assault had occurred, that the aggressor wanted to have sex with the victim, that the victim did not want to have sex with the aggressor, and that the description was more emotionally evocative than after watching a video presentation, despite the fact that the scenes were identical and that the amount of time it took to read or watch was approximately the same.

Overall, participants, regardless of their gender, the gender of the aggressor and victim, or the type of relationship portrayed, agreed that sexual assault had occurred, thought the situation described was emotionally evocative, thought the aggressor wanted to have sex with the victim, and thought the victim did not want to have sex with the aggressor. However, nuances in those overall ratings did emerge. Compared to men, women were more emotionally impacted by the scenarios, thought sexual assault was more likely to have happened, were more likely to think the aggressor wanted to have sex with the victim, and were less likely to think the victim wanted to have sex with the aggressor. Likewise, participants thought sexual assault was less likely to have occurred, that the aggressor was less likely to want to have sex with the victim, and that the victim was more likely to want to have sex with the aggressor in same- than in other-gender relationships. When women were portrayed as the victims, regardless of relationship type, the scenario was the most emotionally evocative.

We found that in other-gender relationships, participants were more likely to perceive sexual assault occurring than in same-gender relationships. One might conclude from our research that same-gender relationships are perceived as less likely to be assaultive than other-gender relationships. It might also be that participants did not have much experience with same-gender relationships so had a harder time imagining them.

In addition to the study of presentation style, aggressor and victim genders, and relationship style, our study makes other unique contributions. Sexual assault scenarios involving long-term dating couples have been rare in research, which has focused more on rape by strangers or new acquaintances (e.g. Smith et al., 1988; \& Hull et al., 2016). In addition, our design enabled us to investigate perceptions of violence in same-gender relationships. Indeed, several participants commented about how appreciative they were that this research used a diversity of relationship scenarios: "Glad you are researching sexual assault in relationships, specifically among same-gender relationships. This is a topic that needs much more attention;" and, "This was the hardest survey I have ever taken. It got me really thinking, evaluating my thoughts and helped me see a lot of biases. I hope it does for everyone else." Participants were unexpectedly cognizant of the fact that sexual assault can happen in both same-gender and other-gender dating relationships, and that both men and women can commit sexual violence. Completely coincidentally, data for this research were collected right at the peak of the 2017-18 media-dominating revelations of \#MeToo and related movements. Due to this synchronous timing, participants may have been unexpectedly familiar with the seriousness and commonality of sexual assault, harassment, and misconduct, in all its potential iterations.

Other participant comments highlighted the importance of sexual assault education and research, as well as the value of exposing people to novel depictions of sexual assault situations. Two students presented with the written, female assailant /male victim scenario remarked, “... The situation could have been avoided with better education/understanding/exposure to testimonies like this," and, "I thought this was an interesting experience to take part in. Opened my eyes to the extent that sexual assault can take." Recently Jeffrey and Barata (2020), based on a series of focus groups with heterosexual men, concluded that presumptions about the male-centeredness of sex (such as men have a biologically-based uncontrollable sex drive, it is natural for men to initiate sex, the progression from initiation to sex is relatively unstoppable in men, and misinterpretation of women leads to violence) may be a productive focus of sexual assault education. In a related study (Mennicke, et al., 2020) found that educational programs might focus on slightly different topics - in particular, level of connection with the university, level of institutional support, and understanding of the meaning of consent. 
Results showed that research participants did not believe that the actions portrayed in the scenarios were acceptable. Hopefully, students will apply their perceptions about sexual violence to real-life situations and relationships. Many respondents revealed that they were survivors of sexual violence, and appreciated the fact that this survey was, as one said, "bringing attention to other students about this issue." This project provided a valuable opportunity to try out a novel, multidisciplinary research technique at a uniquely salient time in history, providing a meaningful addition to the canon of knowledge on sexual assault.

\section{References}

Black, M. C., Basile, K. C., Breiding, M. J., Smith, S. G., Walters, M. L., Merrick, M. T., Chen, J., \& Stevens, M. R. (2011). The National Intimate Partner and Sexual Violence Survey: 2010 Summary Report. Atlanta, GA: National Center for Injury Prevention and Control, Centers for Disease Control and Prevention. Retrieved from https://www.cdc.gov/violenceprevention/pdf/nisvs_executive_summary-a.pdf

Davies, M., Pollard, P., \& Archer, J. (2006). Effects of perpetrator gender and victim sexuality on blame toward male victims of sexual assault. The Journal of Social Psychology, 146(3), 275-291. https://doi.org/10.3200/SOCP.146.3.275-291

Hull, D. B., Hull, J. H., \& Sheplavy, E. (2016). Perceptions of outcomes for men and women in ambiguous date rape scenarios. North American Journal of Psychology, 18(2), 391-404.

Jeffrey, N. K., \& Barata, P. C. (2020). The intersections of normative heterosexuality and sexual violence: university men's talk about sexual behavior in intimate relationships. Sex Roles, 83(5/6), 353. https://doi.org/10.1007/s11199-019-01110-3

McEvoy, A. (2017). Sexual assault in context: Implications for research and practice. Personal collection of A. McEvoy, Northern Michigan University, Marquette, MI.

Mennicke, A., Geiger, E., \& Brewster, M. (2020). Interpersonal violence prevention considerations for sexual minority college students: Lower campus connection, worse perceptions of institutional support, and more accurate understandings of sexual consent. Journal of Family Violence, 35(6), 589-601. Retrieved from https://doi.org/10.1007/s10896-019-00089-5

National Institute of Justice (NIJ). (2008). Most victims know their attacker. Office of Justice Programs. Retrieved from https://nij.ojp.gov/redirect-legacy/topics/crime/rape-sexual-\%20violence/campus/pages/know-attacker.aspx

Office of the Chancellor. (2014). Survey Results: 2014 Community Attitudes on Sexual Assault. Cambridge, MA: Massachusetts Institute of Technology. Retrieved from http://web.mit.edu/surveys/health/MIT-CASA-Survey-Summary.pdf

Ollen, E. W., Ameral, V. E., Palm Reed, K., \& Hines, D. A. (2017). Sexual minority college students' perceptions on dating violence and sexual assault. Journal of Counseling Psychology, 64(1), 112-119. https://doi.org/10.1037/cou0000180

Sims, C. M., Noel, N. E., \& Maisto, S. A. (2007). Rape blame as a function of alcohol presence and resistance type. Addictive Behaviors, 32(12), 2766-2775. https://doi.org/10.1016/j.addbeh.2007.04.013

Sinozich, S., \& Langton, L. (2014). Rape and sexual assault victimization among college-age females, 1995-2013. U.S. Department of Justice, Office of Justice Programs, Bureau of Justice Statistics.

Sleed, M., Durheim, K., Kriel, A., Solomon, V., \& Baxter, V. (2002). The effectiveness of the vignette methodology: A comparison of written and video vignettes in eliciting responses about date rape. South African Journal of Psychology, 32(3), 21-28. https://doi.org/10.1177/008124630203200304

Smith, R. E., Pine, C. J., \& Hawley, M. E. (1988). Social cognitions about adult male victims of female sexual assault. The Journal of Sex Research, 24, 101-111. https://doi.org/10.1080/00224498809551401

\section{Copyrights}

Copyright for this article is retained by the author(s), with first publication rights granted to the journal.

This is an open-access article distributed under the terms and conditions of the Creative Commons Attribution license which permits unrestricted use, distribution, and reproduction in any medium, provided the original work is properly cited. 